\title{
Resistance in Peanut Cultivars and Breeding Lines to Three Root-Knot Nematode Species
}

\author{
W. B. Dong, Department of Plant Pathology, University of Georgia, Coastal Plain Experiment Station, Tifton 31793; \\ C. C. Holbrook and P. Timper, United States Department of Agriculture-Agricultural Research Service, Coastal \\ Plain Experiment Station, Tifton 31793; and T. B. Brenneman, Department of Plant Pathology, and Y. Chu and \\ P. Ozias-Akins, Department of Horticulture, University of Georgia, Coastal Plain Experiment Station, Tifton
}

\begin{abstract}
Dong, W. B., Holbrook, C. C., Timper, P., Brenneman, T. B., Chu, Y., and Ozias-Akins, P. 2008. Resistance in peanut cultivars and breeding lines to three root-knot nematode species. Plant Dis. 92:631-638.

Three major species of root-knot nematode infect peanut: Meloidogyne arenaria race 1, M. hapla, and M. javanica race 3. Sources of resistance to all three nematodes are needed for developing novel peanut cultivars with broad resistance to Meloidogyne spp. Cultivars and breeding lines of peanut were evaluated for resistance to $M$. arenaria, $M$. hapla, and $M$. javanica in the greenhouse and in the laboratory. Twenty-six genotypes with some resistance to $M$. arenaria, $M$. javanica, or $M$. hapla were identified from 60 accessions based on average eggs per gram of root and gall index relative to a susceptible control. Among these, 14 genotypes were moderately to highly resistant to all three species, 5 genotypes were resistant to M. arenaria and M. javanica, 2 genotypes were resistant to $M$. javanica and $M$. hapla, 1 genotype was resistant $M$. arenaria alone, and 4 genotypes were resistant to $M$. hapla alone. Reproduction of $M$. arenaria on lines NR 0817, C724-19-11, and D108 was highly variable, indicating that these genotypes likely were heterogeneous for resistance. COAN, NemaTAM, C724-25-8, and the M. arenariaresistant plants of C724-19-11 contained the dominant sequence-characterized amplified region marker (197/909) for nematode resistance. Results with the molecular markers indicate that the high resistance to $M$. arenaria in GP-NC WS 6 may be different from the resistance in COAN, NemaTAM, and C724-25-8. Resistance to $M$. arenaria was correlated with resistance to $M$. javanica in peanut, whereas resistance to $M$. hapla was not correlated with the resistance to either M. arenaria or M. javanica. The resistant selections should be valuable sources for pyramiding resistance genes to develop new cultivars with broad and durable resistance to Meloidogyne spp.
\end{abstract}

Additional keywords: Arachis hypogaea, greenhouse screening

Root-knot nematodes (Meloidogyne spp.) are among the most serious plant pests in the world. Several species of rootknot nematodes are pathogenic on peanut (Arachis hypogaea L.) and cause considerable yield loss annually. Of these, Meloidogyne arenaria race 1 (Neal) Chitwood, $M$. hapla Chitwood, and $M$. javanica race 3 (Treub) Chitwood are the major pathogenic species of peanut $(2,29)$. These three species are known to occur in many peanut-producing regions, including North, Central and South America, Africa, Asia, Europe, and Australia (34,39). M. arenaria and $M$. javanica are common in warm peanut-growing regions whereas $M$. hapla occurs mainly in cool regions. In the United States, M. arenaria and M. hapla exist throughout the peanut-producing

Corresponding author: W. B. Dong

E-mail: wbdong@uga.edu

Accepted for publication 4 December 2007.

doi:10.1094/PDIS-92-4-0631

(C) 2008 The American Phytopathological Society areas. $M$. arenaria is the predominant species parasitizing peanut in the southern regions, especially in Alabama, Florida, Georgia, Texas, and South Carolina, where up to $40 \%$ of the fields are infested and yield losses in heavily infested fields can exceed $30 \%(27,29,48)$. All three species may cause significant losses in yield and quality of peanut (2). M. hapla is the most prevalent species in more northerly states, including North Carolina, Virginia, and Oklahoma (4,26). Populations of $M$. javanica parasitic on peanut are common in Egypt (47) and India (35), but they are rare in the United States, having been described from only a few fields in Florida, Georgia, and Texas $(28,30,48)$.

Developing cultivars with host resistance to nematodes, which can be defined as the suppression of nematode reproduction by the resistant plant relative to reproduction on a susceptible genotype of the same species (49), is a desirable approach to manage nematodes. Many sources of moderate resistance to $M$. arenaria have been identified from A. hypogaea in the United States germplasm collection $(17,19)$. High levels of resistance to $M$. arenaria exist in Arachis spp. (16,31), and resistance has been introgressed into $A$. hypogaea. Currently, there are six registered interspecific germplasm lines with resistance to $M$. arenaria: TxAG-6 and TxAG-7 (36), GP-NC WS 5 and GP-NC WS 6 (41), and NR 0812 and NR 0817 (3). A backcrossing program was used to introgress the root-knot nematode resistance from TxAG-7 into peanut breeding populations (43). This work resulted in the release of cvs. COAN and NemaTAM, which are highly resistant to $M$. arenaria and $M$. javanica $(37,38)$. The resistance in the two cultivars is governed by a single dominant gene $(8,42)$. However, neither COAN nor NemaTAM has been widely used in agricultural practice due to the low yield potentials relative to the recurrent parent Florunner in noninfested fields (44) and high susceptibility to Tomato spotted wilt virus (TSWV; 20). No peanut cultivars or interspecific germplasm have high levels of resistance to M. hapla (46), although resistance to $M$. hapla has been identified in Arachis hypogaea and related species $(7,13,45)$.

Planting cultivars with currently available sources of nematode resistance may be effective in managing $M$. arenaria and $M$. javanica; but the presence of $M$. hapla throughout the peanut-growing region raises concerns about durability of resistance. Planting cultivars with resistance genes to $M$. arenaria and $M$. javanica may provide a competitive advantage to $M$. hapla and lead to a species shift. In an analogous situation, planting potato cultivars with resistance only to Globodera rostochiensis led to a rapid increase in $G$. pallida, a species unaffected by the resistance (12). Reliance on a single gene for resistance to nematodes also can lead to selection of virulent biotypes. Several populations of $M$. incognita recently have been identified as virulent on tomato with $M i$ in regions where tomato is a major crop $(14,25)$. Additional sources of resistance to root-knot nematodes in peanut are needed to develop new cultivars with broad and durable resistance to Meloidogyne spp.

In order to expedite breeding for nematode resistance, several molecular markers have been developed $(6,9,10,15)$. One random amplified polymorphic DNA (RAPD) marker, Z3/265, was developed from an $\mathrm{F}_{2}$ population of GA6 (A. hypo- 
gaea (PI261942) $\times$ A. cardenasii Krapov. \& W.C. Gregory) backcrossed with PI261942 (15). A 265-bp fragment derived from A. cardenasii was linked at $10 \pm 2.5$ and $14 \pm 2.9$ centimorgans from the putative nematode resistance genes $\mathrm{Mag}$ and Mae, respectively. It was converted suc- cessfully into a sequence-characterized amplified region (SCAR) marker (15). Choi et al. (8) found that the single dominant resistance gene in COAN was linked to restriction fragment length polymorphism (RFLP) markers R2430E and R2545E. Burow et al. (6) identified three

Table 1. Peanut (Arachis hypogaea) genotypes evaluated for resistance to three species of Meloidogyne

\begin{tabular}{|c|c|c|c|}
\hline Name/code ${ }^{a}$ & Origin and type of line & $\begin{array}{c}\text { Known } \\
\text { resistance }^{b}\end{array}$ & $\begin{array}{l}\text { Parent species, } \\
\text { resistance source }\end{array}$ \\
\hline 9509 & China; breeding line & $\mathrm{N}$ & A. hypogaea \\
\hline 950213 & China; breeding line & $\mathrm{N}$ & A. hypogaea \\
\hline 950404 & China; breeding line & $\mathrm{N}$ & A. hypogaea \\
\hline 950521 & China; breeding line & $\mathrm{N}$ & A. hypogaea \\
\hline 950530 & China; breeding line & $\mathrm{N}$ & A. hypogaea \\
\hline 950536 & China; breeding line & $\mathrm{N}$ & A. hypogaea \\
\hline $961308-1$ & China; breeding line & $\mathrm{N}$ & A. hypogaea \\
\hline $961308-2$ & China; breeding line & $\mathrm{N}$ & A. hypogaea \\
\hline 970101 & China; breeding line & $\mathrm{N}$ & A. hypogaea \\
\hline 970105 & China; breeding line & $\mathrm{N}$ & A. hypogaea \\
\hline 990304 & China; breeding line & $\mathrm{N}$ & A. hypogaea \\
\hline 991219 & China; breeding line & $\mathrm{N}$ & A. hypogaea \\
\hline Baisha 1016 & China; cultivar & $\mathrm{N}$ & A. hypogaea \\
\hline C209-6-37 & Georgia, USA; released germplasm line & $\mathrm{Ma}$ & A. cardenasii \\
\hline C724-19-11 & Georgia, USA; breeding line & $\mathrm{Ma}$ & COAN \\
\hline C724-25-8 & Georgia, USA; breeding line & $\mathrm{Ma}$ & COAN \\
\hline C-99R & Florida, USA; cultivar & $\mathrm{N}$ & A. hypogaea \\
\hline COAN & Texas, USA; cultivar & $\mathrm{Ma} \& \mathrm{Mj}$ & A. cardenasii \\
\hline D002 & China; selection & $\mathrm{N}$ & A. hypogaea \\
\hline D009 & China; selection & Mh & A. hypogaea \\
\hline D013 & China; selection & $\mathrm{N}$ & A. hypogaea \\
\hline D0206 & China; selection & $\mathrm{N}$ & A. hypogaea \\
\hline D029 & China; selection & $\mathrm{Mh}$ & A. hypogaea \\
\hline D031 & China; selection & $\mathrm{Mh}$ & A. hypogaea \\
\hline D040 & China; selection & Mh & A. hypogaea \\
\hline D054 & China; selection & $\mathrm{N}$ & A. hypogaea \\
\hline D098 & China; selection & $\mathrm{N}$ & A. hypogaea \\
\hline D099 & China; selection & $\mathrm{Mh}$ & A. hypogaea \\
\hline D108 & North Carolina, USA; breeding line & $\mathrm{N}$ & A. cardenasii \\
\hline D122 & China; selection & $\mathrm{N}$ & A. hypogaea \\
\hline D129 & China; selection & $\mathrm{N}$ & A. hypogaea \\
\hline D131 & China; selection & $\mathrm{N}$ & A. hypogaea \\
\hline D132 & China; selection & $\mathrm{N}$ & A. hypogaea \\
\hline D133 & China; selection & $\mathrm{N}$ & A. hypogaea \\
\hline D134 & North Carolina, USA; breeding line & $\mathrm{N}$ & A. cardenasii \\
\hline D140 & China; selection & $\mathrm{N}$ & A. glabrata \\
\hline D142 & China; selection & $\mathrm{N}$ & A. hypogaea \\
\hline D143 & China; selection & $\mathrm{N}$ & A. hypogaea \\
\hline D169 & China; selection & $\mathrm{N}$ & A. hypogaea \\
\hline D998 & China; selection & $\mathrm{N}$ & A. hypogaea \\
\hline D999 & China; selection & $\mathrm{N}$ & A. hypogaea \\
\hline Florunner & Florida; cultivar & $\mathrm{N}$ & A. hypogaea \\
\hline Georgia Green & Georgia, USA; cultivar & $\mathrm{N}$ & A. hypogaea \\
\hline Georgia-01R & Georgia, USA; cultivar & $\mathrm{N}$ & A. hypogaea \\
\hline Georgia- $02 \mathrm{C}$ & Georgia, USA; cultivar & $\mathrm{N}$ & A. hypogaea \\
\hline GP-NC WS 5 & North Carolina, USA; released germplasm line & Ma & A. cardenasii \\
\hline GP-NC WS 6 & North Carolina, USA; released germplasm line & $\mathrm{Ma}$ & A. cardenasii \\
\hline HT 02-01 & North Carolina, USA; breeding line & $\mathrm{N}$ & GP-NC WS 5 \\
\hline Huayu 17 & China; cultivar & $\mathrm{N}$ & A. hypogaea \\
\hline Huayu 21 & China; cultivar & $\mathrm{N}$ & A. hypogaea \\
\hline Huayu 22 & China; cultivar & $\mathrm{N}$ & A. hypogaea \\
\hline Lianhua 2 & China; cultivar & $\mathrm{N}$ & A. hypogaea \\
\hline Luhua 9 & China; cultivar & $\mathrm{N}$ & A. hypogaea \\
\hline Luhua 11 & China; cultivar & $\mathrm{N}$ & A. hypogaea \\
\hline Luhua 14 & China; cultivar & $\mathrm{N}$ & A. hypogaea \\
\hline NemaTAM & Texas; cultivar & $\mathrm{Ma} \& \mathrm{Mj}$ & A. cardenasii \\
\hline NR 0817 & Georgia, USA; released germplasm line & $\mathrm{Ma}$ & GP-NC WS 5 \\
\hline Qinglan 2 & China; cultivar & $\mathrm{N}$ & A. hypogaea \\
\hline Southern runner & Florida, USA; cultivar & $\mathrm{N}$ & A. hypogaea \\
\hline Tifrunner & Georgia, USA; cultivar & $\mathrm{N}$ & A. hypogaea \\
\hline
\end{tabular}

a Numbers 95xxxx indicate that the cross was made in 1995 and numbers starting with a D were selections from Chinese germplasm and local cultivars.

${ }^{\mathrm{b}} \mathrm{N}$-unknown; $\mathrm{Ma}, \mathrm{Mj}$, and $\mathrm{Mh}=$ resistant to Meloidogyne arenaria, $M$. javanica, and M. hapla, respectively.
RAPD markers (RKN 229, RKN 410, and RKN 440) linked to $M$. arenaria resistance in several breeding populations derived from TxAG-7 in the fifth backcross generation. Marker RKN 440 was identified in the backcross population with a $5.8 \pm 2.1 \%$ recombination rate with the resistance gene derived from either A. cardenasii or A. diogoi Hoehne. Based on the sequence of the RAPD fragment that originated from COAN, a new SCAR marker, 197/909, recently was developed (9). This SCAR marker amplifies fragments from both susceptible and resistant plants but of different molecular weights, thus avoiding false negative classifications caused by failed reactions with dominant markers.

The objectives of this study were to (i) use greenhouse screening methods and molecular markers to identify new resistance sources to $M$. arenaria, $M$. javanica, and M. hapla and (ii) determine the correlations between the resistances to different species of Meloidogyne.

\section{MATERIALS AND METHODS}

Peanut genotypes. In all, 60 peanut genotypes were evaluated in this study. These included 9 cultivars from China; 9 cultivars from the United States; 12 and 5 breeding lines from China and the United States, respectively; 4 released germplasm lines from the United States; and 21 selections from Chinese peanut germplasm and local cultivars (Table 1). Of these, five accessions previously had been reported to have moderate resistance to $M$. hapla (D009, D029, D031, D040, and D099) $(13,40)$; eight accessions (NR 0817 [3], GP-NC WS 5 and GP-NC WS 6 [41], COAN [37], NemaTAM [38], C209-6-37 [18], and C724-19-11 and C724-25-8 [C. C. Holbrook, unpublished]) had high or moderate resistance to $M$. arenaria; and COAN (37) and NemaTAM (38) were reported to be resistant to $M$. javanica.

Nematode inoculum. One isolate each of $M$. arenaria, $M$. hapla, and $M$. javanica was used to evaluate the peanut accessions for resistance. The isolate of $M$. arenaria originated from a peanut field in Tift County, GA. M. javanica and $M$. hapla were isolated from peanut in Texas. The nematodes were cultured alternately on tomato (Lycopersicon esculentum cv. Rutgers) or eggplant (Solanum melongena cv. Blackbeauty) and peanut cv. Georgia Green. Eggs used for inoculum were extracted from roots of tomato or eggplant by use of $0.05 \% \mathrm{NaOCl}$ in water (24). Species identity of the isolates was confirmed by isozyme phenotyping and by a host differential test (33).

Greenhouse resistance screening. The peanut genotypes were evaluated for resistance to $M$. arenaria, $M$. hapla, and $M$. javanica in three separate experiments in a greenhouse with six replicates in each trial. Two seeds were planted in each 10-by-10$\mathrm{cm}^{2}$ pot filled with steam-pasteurized 
(steam heated at $100^{\circ} \mathrm{C}$ for $6 \mathrm{~h}$ ) sandy soil (texture: $85 \%$ sand, $11 \%$ silt, and $4 \%$ clay) and thinned to one plant per pot after germination. Eight thousand nematode eggs were distributed into two holes $(3 \mathrm{~cm}$ deep) at the base of each plant 2 weeks after planting and covered with soil. In the greenhouse, soil temperatures varied between 20 and $35^{\circ} \mathrm{C}$; every experiment was arranged as a randomized complete block design on a bench.

Peanut plants were uprooted and washed clean of soil 60 days after inoculation. Each plant was assessed for root galling based on the following index: $0=$ no galling, $1=$ trace infection with a few small galls, $2=\leq 25 \%, 3=25$ to $50 \%, 4=51$ to $75 \%$, and $5=\geq 75 \%$ of root galled. Roots then were cut into approximately $5-\mathrm{cm}$ pieces, weighed, and agitated in $1 \%$ $\mathrm{NaOCl}$ solution for $5 \mathrm{~min}$. Eggs were collected and rinsed with tap water on nested 150 - and 25- $\mu \mathrm{m}$-pore sieves, and a subsample was counted under $\times 10$ magnification with an inverted microscope. The genotypes selected as resistant to nematodes, based on either gall index or egg number per gram of root, and the susceptible control (Georgia Green) were reevaluated at least one more time to confirm the resistance.

Gall index and egg number data were analyzed with the PROC GLM procedure of SAS (version 9.1; SAS Institute, Inc., Cary, NC). Means for each genotype within one nematode population were calculated with least-squares estimates of marginal means (LSMEANS), and an individual $t$ test was used for mean separation. The correlation coefficients of resistance to different species of Meloidogyne were analyzed by the PROC CORR procedure of SAS.

SCAR marker screening. Newly expanded leaf tissue samples were collected from approximately 30-day-old peanut seedlings in the greenhouse. Total genomic DNA was extracted using the cetyltrimethylammonium bromide method according to Hopkins et al. (21), with several modifications. The DNA was dissolved in Tris-EDTA buffer $(10 \mathrm{mM}$ Tris and 0.1 mM EDTA, $\mathrm{pH}$ 8.0) with $1 \%$ RNase and stored at $4{ }^{\circ} \mathrm{C}$. SCAR makers Z3/265 (15) and $197 / 909$ (9) were used to determine whether the resistance gene or genes were linked to the $M$. arenaria-resistant markers in selected genotypes. In all, $1 \mu$ l of the DNA extract was used for a 25 - $\mu$ l-volume polymerase chain reaction (PCR) reaction. Each PCR reaction was performed with $0.5 \mathrm{U}$ of Hotmaster Taq DNA polymerase (Promega Corp., Madison, WI) using the buffer supplied by the manufacturer containing $25 \mathrm{mM} \mathrm{Mg}^{2+}$ (final reaction concentration, $2.5 \mathrm{mM}$ ). Amplification conditions for both sets of primers were similar: initial denaturation at $95^{\circ} \mathrm{C}$ for $5 \mathrm{~min} ; 40$ cycles of $95^{\circ} \mathrm{C}$ for $30 \mathrm{~s}$, annealing temperature of $60.2^{\circ} \mathrm{C}$ for $30 \mathrm{~s}$, and $72^{\circ} \mathrm{C}$ for
Table 2. Root galling, reproduction of Meloidogyne arenaria, and resistance classification for selected peanut genotypes tested in the greenhouse

\begin{tabular}{lccrc}
\hline Genotype & No. of replicates $^{\mathbf{a}}$ & Gall index $^{\mathbf{b}}$ & Eggs/g of root & Resistance $^{\mathbf{d}}$ \\
\hline NemaTAM & 17 & $0.64 \pm 0.25$ & $586 \pm 1,041$ & $\mathrm{HR}$ \\
GP-NC WS & 12 & $0.37 \pm 0.31$ & $875 \pm 1,249$ & $\mathrm{HR}$ \\
COAN & 16 & $1.15 \pm 0.27$ & $889 \pm 1,074$ & $\mathrm{HR}$ \\
C724-25-8 & 18 & $0.78 \pm 0.25$ & $1,073 \pm 1,011$ & $\mathrm{HR}$ \\
D054 & 16 & $1.92 \pm 0.25$ & $1,341 \pm 1,074$ & $\mathrm{MR}$ \\
D031 & 16 & $1.42 \pm 0.25$ & $1,428 \pm 1,074$ & MR \\
D040 & 16 & $1.47 \pm 0.25$ & $1,879 \pm 1,074$ & MR \\
D998 & 16 & $1.50 \pm 0.26$ & $2,386 \pm 1,074$ & MR \\
D099 & 16 & $0.95 \pm 0.27$ & $2,439 \pm 1,074$ & MR \\
D009 & 16 & $1.79 \pm 0.26$ & $2,491 \pm 1,073$ & MR \\
950530 & 12 & $2.23 \pm 0.31$ & $2,836 \pm 1,248$ & MR \\
D108 & 18 & $1.00 \pm 0.26$ & $2,917 \pm 1,041$ & MR \\
990304 & 15 & $1.69 \pm 0.28$ & $3,393 \pm 1,110$ & MR \\
950521 & 11 & $1.16 \pm 0.33$ & $3,705 \pm 1,304$ & MR \\
970101 & 10 & $1.97 \pm 0.34$ & $3,852 \pm 1,367$ & MR \\
NR 0817 & 11 & $1.86 \pm 0.33$ & $4,166 \pm 1,304$ & MR \\
C724-19-11 & 17 & $1.94 \pm 0.25$ & $4,597 \pm 1,011$ & MR \\
C209-6-37 & 16 & $2.45 \pm 0.26$ & $4,609 \pm 1,073$ & MR \\
D999 & 10 & $1.85 \pm 0.31$ & $4,611 \pm 1,367$ & MR \\
HTS 02-01 & 10 & $2.34 \pm 0.34$ & $4,670 \pm 1,369$ & MR \\
950213 & 10 & $3.89 \pm 0.31$ & $6,337 \pm 1,367$ & S \\
GP-NC WS 5 & 11 & $3.45 \pm 0.33$ & $11,046 \pm 1,304$ & S \\
Georgia Green & 18 & $4.14 \pm 0.25$ & $11,069 \pm 1,011$ & S \\
\hline
\end{tabular}

${ }^{a}$ Data from three trials (six replicates/trial) were combined for analysis as unbalanced data.

${ }^{\mathrm{b}}$ Gall index, where $0=$ no galling, $1=$ trace infection with a few small galls, $2=\leq 25 \%, 3=25$ to $50 \%, 4=51$ to $75 \%$, and $5=>75 \%$ of roots galled. Data were least-squares estimates of marginal means (LSMEANs) \pm standard errors.

${ }^{c}$ Data were LSMEANs \pm standard errors.

${ }^{\mathrm{d}} \mathrm{HR}=$ highly resistant, eggs/g of root $\leq 10 \%$ of Georgia Green; MR = moderately resistant, eggs/g of root $\leq 50 \%$ of Georgia Green and gall index $=\leq 3.00$; and $\mathrm{S}=$ susceptible, eggs/g of root $>50 \%$ of Georgia Green or gall index $>3.00$.
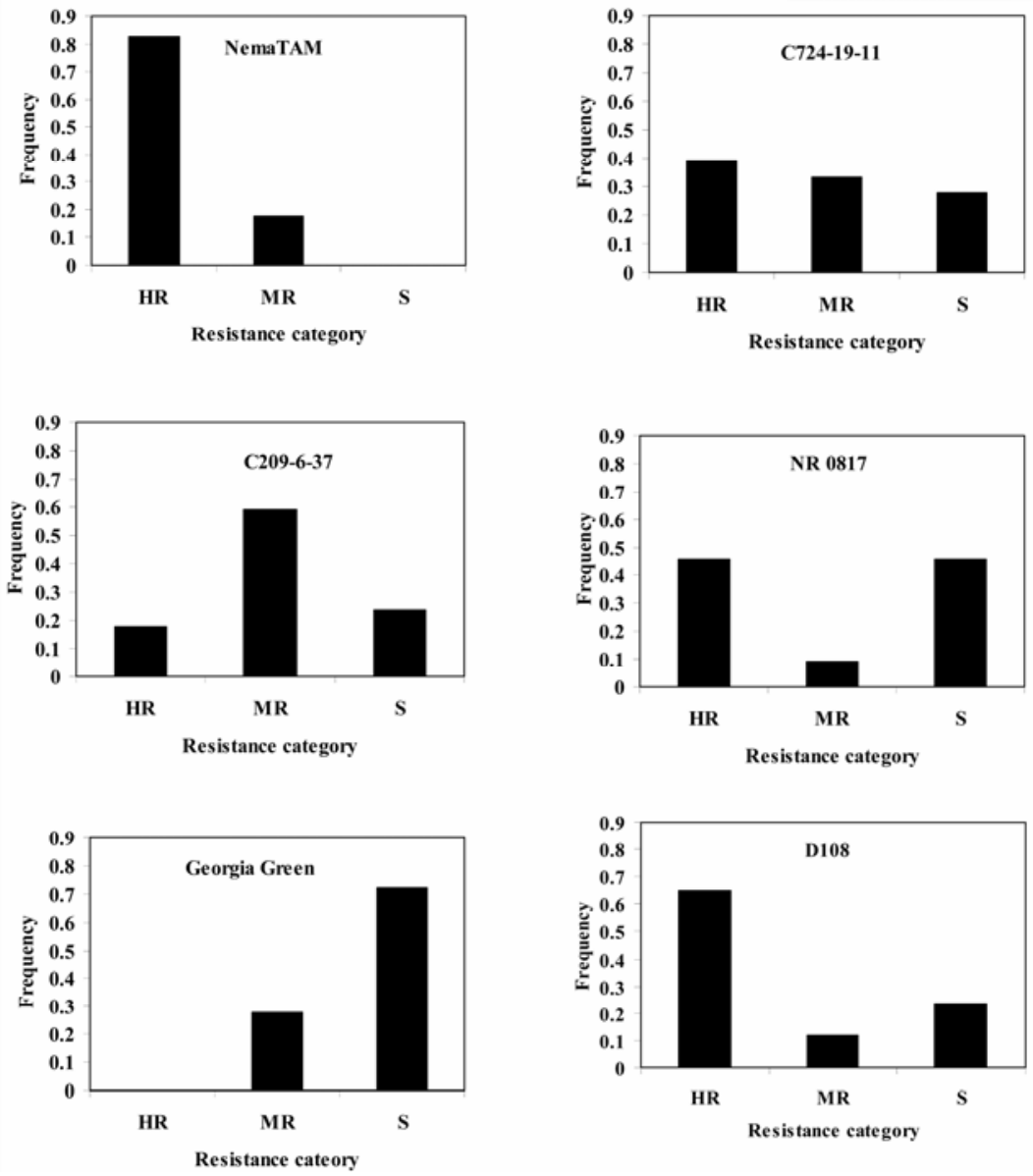

Fig. 1. Frequency of individuals with different levels of resistance to Meloidogyne arenaria in peanut genotypes. NemaTAM was classified as highly resistant (HR), C209-6-37 was classified as moderately resistant (MR), and Georgia Green was the susceptible (S) control. 
$30 \mathrm{~s}$; and final extension at $72^{\circ} \mathrm{C}$ for $7 \mathrm{~min}$. All PCR amplifications were performed with the GeneAmp PCR system 9700 (Applied Biosystems, Foster City, CA). PCR products were separated on $2 \%$ agarose gels (Invitrogen, Carlsbad, CA) and 8\% polyacrylamide (PAGE) gels.

\section{RESULTS}

M. arenaria. Fifty-seven genotypes were included in the first greenhouse screening trial for resistance to $M$. arenaria. The second greenhouse trial evaluated 28 accessions with low gall indices $(\leq 3.0)$ or low egg numbers $(\leq 50 \%$ of the susceptible control Georgia Green), as well as two genotypes that did not germinate in trial 1 , three new collections, and susceptible control Georgia Green. Of these entries, 21 accessions with low gall indices or low egg numbers were selected and advanced to the third trial with Georgia Green as the susceptible control. Genotype GP-NC WS 5 also was included in trial 3, although it had a high gall index and eggs per gram of root in the earlier trials. There were no significant interactions of genotype-trial for gall index and eggs per gram of root; thus, data for the genotypes included in all three trials or in the second and the third trials were pooled across trials. The data was analyzed with GLM of SAS as unbalanced data set (Table 2). Eggs per gram of root for all the selected genotypes, except GP-NC WS 5, were lower $(P \leq 0.05)$ than the susceptible control Georgia Green. Reproduction of $M$. arenaria on genotypes NemaTAM, GPNC WS 6, COAN, and C724-25-8 were less than $10 \%$ of Georgia Green, and they
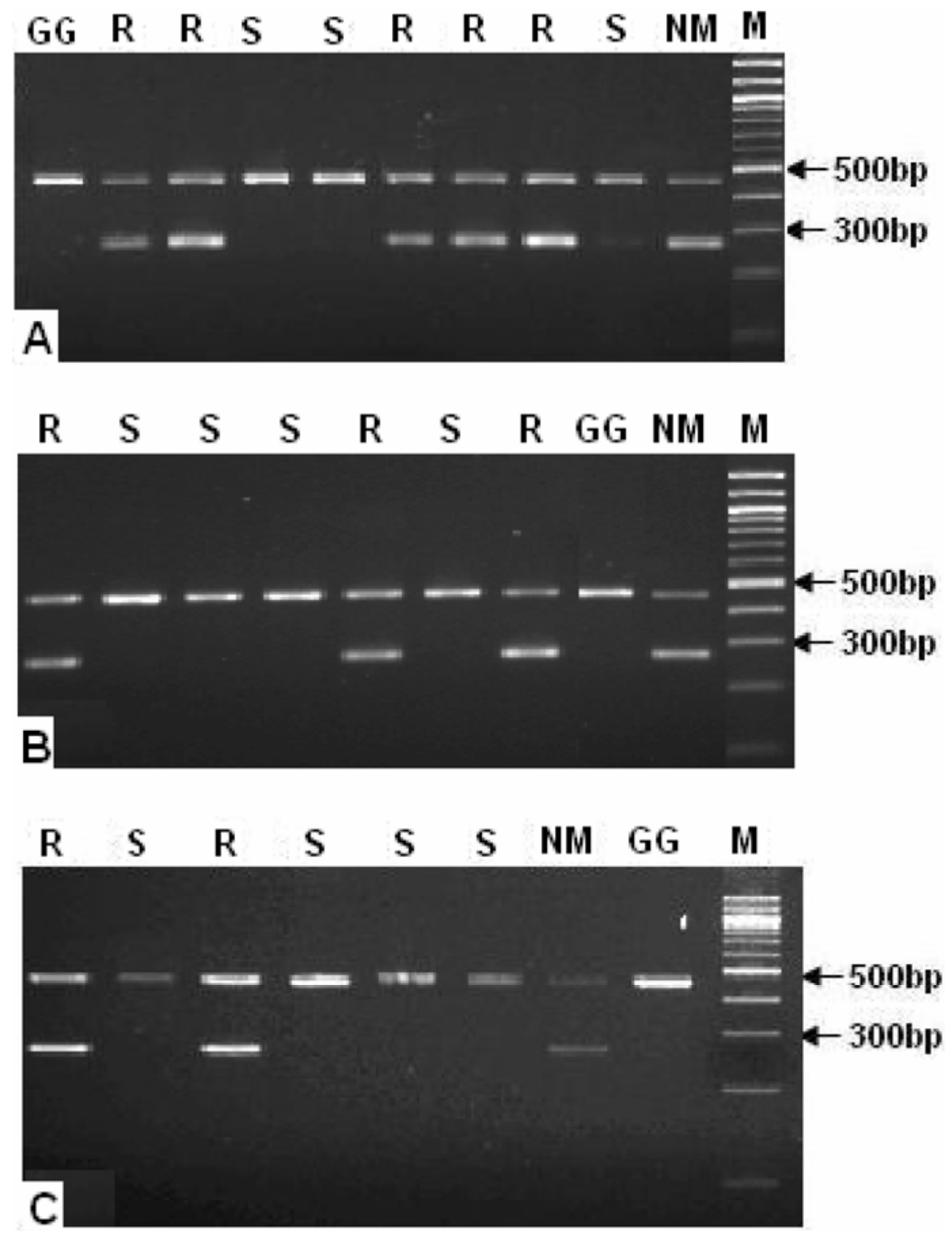

Fig. 2. Polymerase chain reaction (PCR) amplification by primer sets 400/401 and 199/200 for individuals of A, C724-19-11, B, NR 0817, and C, D108. Set 400/401 amplified actin depolymerizing factor an endogenous gene. It serves as a positive control for sources of PCR amplification. Set 199/200 was a Meloidogyne arenaria-resistant sequence-characterized amplified region marker (Z3/265). GG: Georgia Green (susceptible control), NM: NemaTAM (resistant control), R: highly resistant individual in greenhouse screening, and S: susceptible individual in greenhouse screening.

were classified as highly resistant (HR) Sixteen genotypes were classified as moderately resistant (MR) because nematode reproduction was $<50 \%$ of Georgia Green. The genotypes 950213 and GP-NC WS 5 were classified as susceptible (S). On all the HR and MR genotypes, gall indices were $\leq 3.00$.

The variability of egg numbers for NR 0817, C724-19-11, and D108 was extremely high, and the frequencies of individual plants with different resistance levels for these three genotypes were different from NemaTAM (highly resistant), C2096-37 (MR), or Georgia Green (susceptible) (Fig. 1). Genotypes NR 0817, C724-19-11, and D108 showed high frequencies in both $\mathrm{HR}$ and S categories, and low in MR, although they were ranked in the MR group. This suggests that these three genotypes were segregating. The resistant phenotype of the SCAR marker Z3/265 was detected in five $(62.5 \%)$, three $(42.9 \%)$, and two (33.3\%) individuals of NR 0817, C72419-11, and D108, respectively. Those plants showing the marker were scored HR in the greenhouse screening, whereas the others showed a susceptible band pattern with one exception in C724-19-11 (Fig. 2).

M. javanica. In all, 57, 34, and 24 genotypes were included in the $M$. javanica screening trials 1,2 , and 3 , respectively. Trials 2 and 3 included resistant selections from the previous trial, new collections, and the susceptible control Georgia Green. Data for those genotypes that were tested in three or the last two trials were pooled and analyzed because there were no significant interactions between genotypes and trials for gall index and eggs per gram of root (Table 3). All the selected genotypes, except GP-NC WS 5, showed lower $(P \leq 0.05)$ eggs per gram of root and gall indices than the $\mathrm{S}$ control Georgia Green. The eggs per gram of root for genotypes C724-25-8, NemaTAM, and COAN were less than $10 \%$ of the $\mathrm{S}$ control, and these three genotypes were classified as HR. Based on both eggs per gram of root and gall index, 18 genotypes were classified in the MR group. On genotypes HTS 02-01 and GP-NC WS 5, M. javanica produced over $50 \%$ of the eggs produced on Georgia Green; therefore, these two genotypes were classified as $\mathrm{S}$.

M. hapla. In all, 57, 37, and 26 genotypes were included in the $M$. hapla screening trials 1,2 , and 3 , respectively. Trials 2 and 3 included resistant selections from the previous trial, new collections, and an S control, Georgia Green. Data for those genotypes, which were included in all three or in the last two trials, were combined for analysis. Compared with $M$. arenaria and $M$. javanica, the galls caused by $M$. hapla were smaller and the symptoms on root systems were less severe. Therefore, the gall index standard which was used to identify the resistant geno- 
types to M. hapla was modified from that for M. arenaria and M. javanica. The gall indices for the genotypes that were classified as highly or moderately resistant to $M$. hapla were $\leq 2$ rather than $\leq 3.0$ for $M$. arenaria and $M$. javanica. The genotypes GP-NC WS 5, HTS 02-01, D108, and NemaTAM supported the same amount of $M$. hapla reproduction as the $\mathrm{S}$ control Georgia Green (Table 4). The genotypes D031, 970105, and 990304 were HR to $M$. hapla, with $<10 \%$ of the eggs per gram of root of Georgia Green. Eighteen genotypes with $\leq 50 \%$ of the eggs per gram of root on Georgia Green and low gall indices $(\leq 2.0)$ were MR.

SCAR marker phenotypes. In total, 27 genotypes, including 26 selected genotypes with high or moderate resistance to one or more of the three Meloidogyne spp. and the susceptible control (Georgia Green), were evaluated with the SCAR markers Z3/265 and 197/909. On 2.5\% agarose gel, the marker $Z 3 / 265$ produced a strong resistance band at $265 \mathrm{bp}$ on the genotypes COAN, NemaTAM, C724-25-8, GP-NC WS 6, and some individuals of C724-19-11, D108, and NR 0817 (Fig. 3). This set of primers also produced a faint resistance band on the genotypes 970105 , 991219, D040, D031, HTS 02-01, and some individuals of C724-19-11, which were MR or $\mathrm{S}$ to $M$. arenaria in the greenhouse (Figs. 3 and 2A). The S control Georgia Green and the other genotypes did not show any specific bands.

On $8 \%$ polyacrylamide gel, the marker $197 / 909$ amplified the M. arenariaresistant band on NemaTAM, COAN, C724-25-8, and some individuals of C724-19-11 with high resistance to $M$. arenaria and $M$. javanica, but not on GPNC WS 6 and some individuals of NR 0817 and D108 that also showed high resistance to $M$. arenaria in the greenhouse. The PCR product from NR 0817 was approximately $260 \mathrm{bp}$, even smaller than that from $M$. arenaria-susceptible genotype Georgia Green. The genotype 970105 showed two major bands, which might be an indication of heterozygosity. The other genotypes with moderate resistance to $M$. arenaria or with moderate to high resistance to $M$. javanica and $M$. hapla showed the $M$. arenaria-susceptible band pattern (Fig. 4).

Correlations for resistance to $M$. arenaria, M. javanica, and M. hapla. Of 60 genotypes, 26 were identified with some resistance to $M$. arenaria, $M$. javanica, or M. hapla. For the 26 resistance selections and Georgia Green, gall indices caused by $M$. arenaria were correlated with gall indices caused by $M$. javanica ( $r=0.7498, P=0.0015)$. However, the resistance to $M$. hapla did not show any significant correlations to resistance to either $M$. arenaria $(r=0.2188, P$ $>0.05)$ or $M$. javanica $(r=0.3256, P>$ $0.05)$.
Table 3. Root galling, reproduction of Meloidogyne javanica, and resistance classification for selected peanut genotypes tested in the greenhouse

\begin{tabular}{|c|c|c|c|c|}
\hline Genotype & No. of replicates ${ }^{a}$ & Gall index ${ }^{b}$ & Eggs/g of root ${ }^{c}$ & Resistance $^{d}$ \\
\hline C724-25-8 & 15 & $0.59 \pm 0.29$ & $519 \pm 939$ & HR \\
\hline NemaTAM & 16 & $0.62 \pm 0.28$ & $703 \pm 908$ & HR \\
\hline COAN & 17 & $0.60 \pm 0.27$ & $899 \pm 880$ & HR \\
\hline 991219 & 8 & $0.96 \pm 0.40$ & $1,560 \pm 1,299$ & MR \\
\hline 950530 & 12 & $1.34 \pm 0.32$ & $1,757 \pm 1,057$ & MR \\
\hline D009 & 13 & $1.57 \pm 0.31$ & $1,782 \pm 1,011$ & MR \\
\hline D031 & 13 & $1.44 \pm 0.30$ & $2,204 \pm 1,009$ & MR \\
\hline 950521 & 18 & $1.17 \pm 0.26$ & $2,497 \pm 854$ & MR \\
\hline D099 & 16 & $1.57 \pm 0.28$ & $2,657 \pm 908$ & MR \\
\hline D040 & 16 & $1.77 \pm 0.27$ & $2,996 \pm 908$ & MR \\
\hline D108 & 18 & $0.86 \pm 0.26$ & $3,000 \pm 854$ & MR \\
\hline D998 & 10 & $2.47 \pm 0.32$ & $3,013 \pm 1,158$ & MR \\
\hline 990304 & 13 & $1.85 \pm 0.31$ & $3,050 \pm 1,009$ & MR \\
\hline D054 & 18 & $1.67 \pm 0.26$ & $3,283 \pm 854$ & MR \\
\hline D999 & 12 & $1.72 \pm 0.32$ & $3,343 \pm 1,057$ & MR \\
\hline GP-NC WS 6 & 10 & $1.29 \pm 0.35$ & $3,544 \pm 1,161$ & MR \\
\hline NR 0817 & 15 & $2.05 \pm 0.29$ & $3,624 \pm 937$ & MR \\
\hline 970101 & 9 & $1.81 \pm 0.37$ & $3,841 \pm 1,221$ & MR \\
\hline C724-19-11 & 11 & $1.91 \pm 0.33$ & $4,070 \pm 1,100$ & MR \\
\hline D002 & 18 & $1.83 \pm 0.26$ & $4,237 \pm 854$ & MR \\
\hline C209-6-37 & 18 & $2.53 \pm 0.26$ & $4,804 \pm 854$ & MR \\
\hline HTS 02-01 & 12 & $2.58 \pm 0.32$ & $6,996 \pm 1,057$ & S \\
\hline GP-NC WS 5 & 10 & $2.88 \pm 0.35$ & $8,708 \pm 1,160$ & $\mathrm{~S}$ \\
\hline Georgia Green & 14 & $4.49 \pm 0.28$ & $10,318 \pm 972$ & $\mathrm{~S}$ \\
\hline
\end{tabular}

a Data from three trials (six replicates/trial) were combined for analysis as unbalanced data.

b Gall index, where $0=$ no galling, $1=$ trace infection with a few small galls, $2=\leq 25 \%, 3=25$ to $50 \%, 4=51$ to $75 \%$, and $5=>75 \%$ of roots galled. Data were least-squares estimates of marginal means (LSMEANs) \pm standard errors.

c Data were LSMEANs \pm standard errors.

${ }^{\mathrm{d}} \mathrm{HR}=$ highly resistant, eggs/g of root $\leq 10 \%$ of Georgia Green; MR = moderately resistant, eggs/g of root $\leq 50 \%$ of Georgia Green and gall index $=\leq 3.00$; and $\mathrm{S}=$ susceptible, eggs/g of root $>50 \%$ of Georgia Green or gall index $>3.00$.

Table 4. Root galling, reproduction of Meloidogyne hapla reproduction, and resistance classification for selected peanut genotypes tested in the greenhouse

\begin{tabular}{|c|c|c|c|c|}
\hline Genotype & No. of replicates ${ }^{a}$ & Gall index ${ }^{b}$ & Eggs/g of root ${ }^{c}$ & Resistance $^{d}$ \\
\hline 970105 & 9 & $0.31 \pm 0.39$ & $550 \pm 1,745$ & HR \\
\hline D031 & 12 & $0.43 \pm 0.34$ & $631 \pm 1,505$ & HR \\
\hline 990304 & 10 & $0.25 \pm 0.37$ & $811 \pm 1,653$ & HR \\
\hline 950530 & 11 & $0.68 \pm 0.35$ & $985 \pm 1,574$ & MR \\
\hline D099 & 14 & $0.46 \pm 0.34$ & $1,087 \pm 1,505$ & MR \\
\hline D009 & 12 & $0.38 \pm 0.34$ & $1,149 \pm 1,505$ & MR \\
\hline COAN & 9 & $0.87 \pm 0.39$ & $1,180 \pm 1,745$ & MR \\
\hline Luhua 14 & 12 & $1.88 \pm 0.34$ & $1,712 \pm 1,505$ & MR \\
\hline $961308-1$ & 11 & $0.71 \pm 0.34$ & $1,769 \pm 1,574$ & MR \\
\hline D999 & 12 & $0.87 \pm 0.34$ & $1,790 \pm 1,505$ & MR \\
\hline Huayu 21 & 11 & $0.91 \pm 0.35$ & $1,879 \pm 1,574$ & MR \\
\hline C724-19-11 & 11 & $1.54 \pm 0.34$ & $1,904 \pm 1,574$ & MR \\
\hline 991219 & 16 & $0.50 \pm 0.34$ & $1,988 \pm 1,505$ & MR \\
\hline D054 & 11 & $0.51 \pm 0.35$ & $1,997 \pm 1,574$ & MR \\
\hline D040 & 12 & $0.38 \pm 0.34$ & $2,084 \pm 1,505$ & MR \\
\hline D998 & 14 & $0.50 \pm 0.34$ & $2,456 \pm 1,505$ & MR \\
\hline 970101 & 12 & $0.87 \pm 0.34$ & $3,350 \pm 1,505$ & MR \\
\hline D002 & 12 & $0.83 \pm 0.34$ & $3,376 \pm 1,505$ & MR \\
\hline NR 0817 & 8 & $1.07 \pm 0.41$ & $4,074 \pm 1,848$ & MR \\
\hline GP-NC WS 6 & 12 & $1.50 \pm 0.34$ & $4,103 \pm 1,505$ & MR \\
\hline C724-25-8 & 13 & $1.25 \pm 0.34$ & $4,393 \pm 1,505$ & S \\
\hline D108 & 13 & $1.04 \pm 0.34$ & $7,695 \pm 1,505$ & $\mathrm{~S}$ \\
\hline NemaTAM & 12 & $2.17 \pm 0.34$ & $7,706 \pm 1,505$ & $\mathrm{~S}$ \\
\hline Georgia Green & 15 & $2.87 \pm 0.34$ & $8,739 \pm 1,505$ & $\mathrm{~S}$ \\
\hline HTS 02-01 & 10 & $3.02 \pm 0.37$ & $9,192 \pm 1,653$ & $\mathrm{~S}$ \\
\hline GP-NC WS 5 & 12 & $2.83 \pm 0.34$ & $11,348 \pm 1,505$ & $\mathrm{~S}$ \\
\hline
\end{tabular}

${ }^{a}$ Data from three trials (six replicates/trial) were combined for analysis as unbalanced data.

${ }^{\mathrm{b}}$ Gall index, where $0=$ no galling, $1=$ trace infection with a few small galls, $2=\leq 25 \%, 3=25$ to $50 \%, 4=51$ to $75 \%$, and $5=>75 \%$ of roots galled. Data were least-squares estimates of marginal means (LSMEANs) \pm standard errors.

c Data were LSMEANs \pm standard errors.

${ }^{\mathrm{d}} \mathrm{HR}=$ highly resistant, eggs/g of root $\leq 10 \%$ of Georgia Green; MR $=$ moderately resistant, eggs/g of root $\leq 50 \%$ of Georgia Green and gall index $=\leq 2.00$; and $\mathrm{S}=$ susceptible, eggs/g of $\operatorname{root}>50 \%$ of Georgia Green or gall index $>2.00$. 


\section{DISCUSSION}

Some of the peanut genotypes evaluated in this study were known to be resistant to one or more Meloidogyne spp. For the most part, our results support previous findings, such as the high resistance to $M$. arenaria and $M$. javanica in COAN and NemaTAM $(37,38)$, high resistance to $M$. arenaria in GP-NC WS 6 (41), and moderate resistance in C209-6-37 (18). Our results also indicated that there existed moderate resistance to $M$. hapla in COAN, which is consistent with the finding of Timper et al. (46). NemaTAM was classified as susceptible to $M$. hapla, although NemaTAM was derived from the same backcross introgression pathway as COAN and the same genes resistant to $M$. arenaria and $M$. javanica. The resistance to $M$. hapla in COAN may have been lost in NemaTAM during the two additional backcross generations with Florunner. We also obtained some conflicting results from previous reports. The genotype GP-NC WS 5 (41) was released as an M. arenariaresistant breeding line, and has been used as the resistant parent to develop additional germplasm with nematode resistance (3). However, in our study, it was extremely susceptible. Perhaps GP-NC WS 5 was not completely homogeneous when it was released, and the seed that we used in this study were collected from susceptible plants. The genotype NR 0817 (3) also was released as an $M$. arenaria-resistant breeding line; however, in this study, it was clas- sified as MR, mainly due to a mixture of resistant and susceptible individuals. The results indicate that the genotypes NR 0817, C724-19-11, and D108 are still segregating for resistance; therefore, further selection is needed before they would be good sources of nematode resistance for peanut breeding programs.

High levels of resistance to $M$. arenaria have been identified in wild Arachis spp. (31). The different mechanisms of resistance that exist in the wild Arachis spp. suggest that different genes for resistance exist in different wild species $(32,42)$. High levels of resistance to $M$. arenaria in A. cardenasii were reported to be conditioned by at least two dominant genes (15) and are expressed as a hypersensitive-like reaction with few second-stage juveniles showing signs of development (31). The germplasm TxAG-6, an interspecific Arachis hybrid developed from a cross made in Texas between A. batizocoi Krapov. \& W. C. Gregory and (A. cardenasii $\times A$. diogoi), was the source of the resistance in COAN, NemaTAM, C724-25-8, and C724-19-11 (37,38; C. C. Holbrook, unpublished). The results of RFLP markers indicated that the resistance in COAN and NemaTAM was derived from A. cardenasii and segregates as a single dominant gene $(8,10)$. However, the resistance in COAN does not appear to involve a necrotic hypersensitive response and may be due to constitutive factors in the roots (5). The gene or genes conditioning hypersensitive response in A. cardenasii may not have been introgressed into COAN. In addition, a recessive gene for resistance to $M$. arenaria has been identified in TxAG-6 (11); however, it is not known if this recessive gene exists in COAN and NemaTAM. The resistance in GP-NC WS 6 and NR 0817 originated from a cross made in North Carolina between $A$. cardenasii and A. hypogaea $(3,41)$. Two dominant genes conferring resistance to $M$. arenaria were identified in GP-NC WS 6: Mae conditions resistance to egg production and Mag conditions resistance to gall formation $(15,41)$. There is no evidence that Mae is the same gene that suppresses egg production in COAN. We have shown the presence of SCAR marker Z3/265 in both COAN and GP-NC WS6 and the absence of SCAR marker 197/909 in GP-NC WS 6, suggesting that the resistant genes in the genotypes derived from the two different introgression pathways may be different. Moreover, resistance in other genotypes which were moderately resistant to $M$. arenaria, such as D054, D031, D040, D099, and so on, also may be conditioned by different genes because all these genotypes are A. hypogaea without any introgression from wild species.

The SCAR marker Z3/265 was developed from an $\mathrm{F}_{2}$ population of GA6, which originated from a cross made in North Carolina. In our results, this marker exists in the genotypes with resistance genes derived from both the North Carolina cross

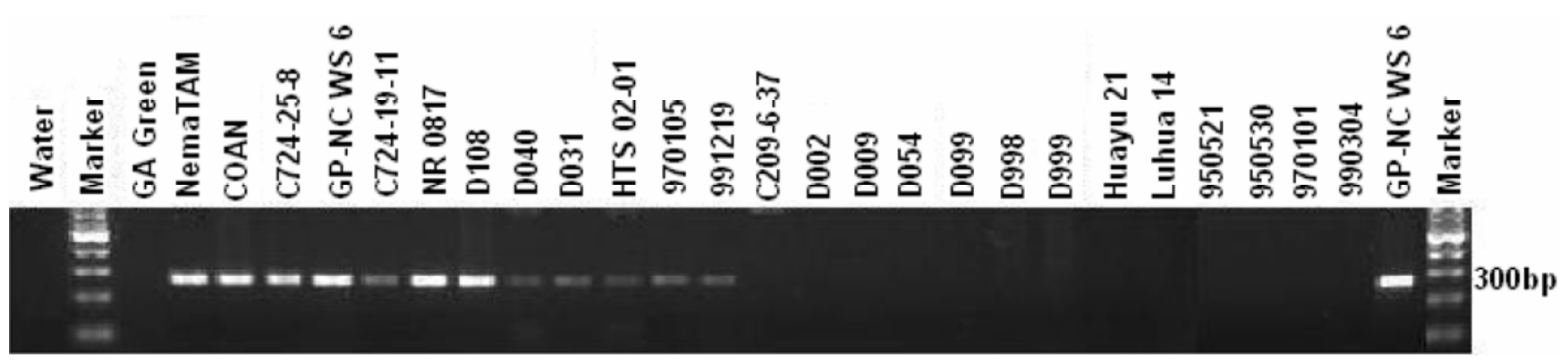

Fig. 3. Separation of amplicons from selected peanut genotypes with primers $199 / 200$ on $2.5 \%$ agarose gel.

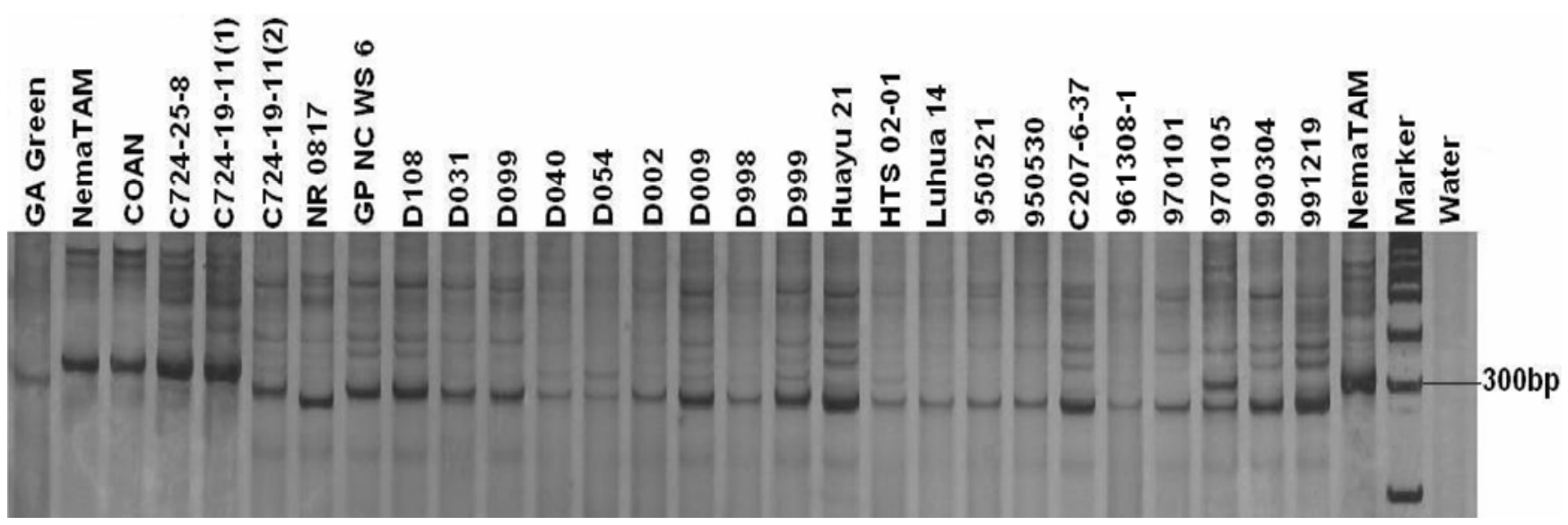

Fig. 4. Separation of amplicons from selected peanut genotypes with primers 197/909 on 8\% polyacrylamide gel. C724-19-11(1) and C724-19-11(2) were two individuals of the same breeding line. 
and Texas cross. It also is present in some M. arenaria-susceptible genotypes with or without any introgression from wild species. This confirmed a previous finding that $\mathrm{Z} 3 / 265$ can produce a false positive score (9). The SCAR marker $197 / 909$ was developed based on the sequence of an RAPD fragment that originated from COAN (9). This marker shows a high correlation with the greenhouse phenotype data. It amplifies fragments from both susceptible and resistant samples but of different molecular weights, avoiding false negatives. However, this marker is present only in the genotypes directly related to the resistance gene derived from the TxAG-7.

In this study, we found that resistance to $M$. arenaria and $M$. javanica was highly correlated, indicating that, in many peanut genotypes, the same gene or genes may confer resistance to both species, or the resistance genes for each species are closely linked. This was different from the previous observations with the interspecific hybrid TxAG-7, in which the resistance to Meloidogyne spp. segregated independently (1). Our study also showed that resistance to M. hapla was not correlated with resistance to $M$. arenaria or $M$. javanica. The mechanisms of resistance to M. hapla may be different from that of $M$. arenaria and $M$. javanica. The difference between resistance to $M$. arenaria and resistance to M. hapla may not be caused by differences in their parasitism gene. Recent evidence suggests that $M$. arenaria, $M$. javanica, $M$. hapla, and $M$. incognita may have identical parasitism genes $(22,23)$. Therefore, the resistance genes in peanut may be related to differential recognition by the plant of the three Meloidogyne spp.

In summary, the data presented in this report showed that resistance to all three Meloidogyne spp. exists within cultivated peanut (A. hypogaea), either with or without introgressed genes from wild species. We identified several additional genotypes with moderate resistance to $M$. arenaria and $M$. javanica, such as D009, D031, D040, D054, D099, D998, D999, 950521, 950530, 970101, and 990304. The level of resistance in these genotypes was as good as or better than the resistance in the MR genotype C209-6-37. These genotypes may have different resistance genes from released $M$. arenaria-resistant germplasm $(3,36,41)$ because they do not have introgressed genes from wild species. We identified peanut genotypes with high and moderate resistance to $M$. hapla. The $3 \mathrm{HR}$ genotypes and most of the 18 MR genotypes do not have introgressed genes from wild species, whereas some MR genotypes, such as C724-19-11, COAN, NR 0817, GP-NC WS 6, and C724-25-8, have introgressed genes. Although the genetics of the resistance to M. hapla in peanut has not been determined, we believe that the selected genotypes will be valuable for developing new peanut cultivars with broad and durable resistances to Meloidogyne spp.

\section{ACKNOWLEDGMENTS}

This study was funded in part by the Georgia Peanut Commission. We thank D. Mauldin, J. Golden, and W. H. Wilson for their assistance in greenhouse screening; and E. P. Morgan, X. Shen, and $\mathrm{B}$. Wang for their technical assistance for molecular marker lab work.

\section{LITERATURE CITED}

1. Abdel-Momen, S. M., Simpson, C. E., and Starr, J. L. 1998. Resistance of interspecific Arachis breeding lines to Meloidogyne javanica and an undescribed Meloidogyne species. J. Nematol. 30:341-346.

2. Abdel-Momen, S. M., and Starr, J. L. 1997. Damage functions for three Meloidogyne species on Arachis hypogaea in Texas. J. Nematol. 29:478-483.

3. Anderson, W. F., Holbrook, C. C., and Timper, P. 2006. Registration of root-knot nematode resistant peanut germplasm lines NR 0812 and NR 0817. Crop Sci. 46:481-482.

4. Anonymous. 1987. Bibliography of estimated crop losses in the United States due to plantparasitic nematode. Ann. Appl. Nematol. Suppl. J. Nematol. 1:6-12.

5. Bendezu, I. F., and Starr, J. L. 2003. Mechanism of resistance to Meloidogyne arenaria in the peanut cultivar COAN. J. Nematol. 35:115118.

6. Burow, M. D., Starr, J. L., Paterson, A. H., and Simpson, C. E. 1996. Identification of peanut (Arachis hypogaea L.) RAPD markers diagnostic of root-knot nematode (Meloidogyne arenaria (Neal) Chitwood) resistance. Mol. Breed. 2:369-379.

7. Castillo, M. B., Morrison, L. S., Russell, C. C., and Banks, D. J. 1973. Resistance to Meloidogyne hapla in peanut. J. Nematol. 5:281285.

8. Choi, K., Burow, M. D., Church, G., Patterson, A. H., Simpson, C. E., and Starr, J. L. 1999. Genetics and mechanism of resistance to Meloidogyne arenaria in peanut germplasm. J. Nematol. 31:283-290.

9. Chu, Y., Holbrook, C. C., Timper, P., and Ozias-Akins, P. 2007. Development of PCRbased molecular marker to select for nematode resistance in peanut. Crop Sci. 47:841-847.

10. Church, G. T., Simpson, C. E., Burow, M. D., Paterson, A. H., and Starr, J. L. 2000. Use of RFLP markers for identification of individuals homozygous for resistance to Meloidogyne arenaria in peanut. Nematology 2:575-580.

11. Church, G. T., Starr, J. L., and Simpson, C. E. 2005. A recessive gene for resistance to Meloidogyne arenaria in interspecific Arachis spp. hybrids. J. Nematol. 37:178-184.

12. Cook, R., and Evans, K. 1987. Resistance and tolerance. Pages 179-221 in: Principles and Practice of Nematode Control in Crops. R. H. Brown and B. R. Kerry, eds. Academic Press, Sydney, Australia.

13. Dong, W. B, Shi, Y. M., Zhao, Z. Q., and Yu, S. L. 2001. Stability of peanut germplasm resistance to root-knot nematode (Meloidogyne hapla Chitwood). J. Shenyang Agric. Univ. 32:17-21.

14. Eddaoudi, M., Ammati, M., and Rammah, M. 1997. Identification of the resistance breaking of populations of Meloidogyne on tomatoes in Morocco and their effect on new sources of resistance. Fundam. Appl. Nematol. 20:285-289.

15. Garcia, G. M., Stalker, H. T., Shoroeder, E., and Kochert, G. 1996. Identification of RAPD, SCAR, and RFLP markers tightly linked to nematode resistance genes introgressed from Arachis cardenasii into Arachis hypogaea. Genome 39:836-845.
16. Holbrook, C. C., and Noe, J. P. 1990. Resistance to Meloidogyne arenaria in Arachis spp. and the implications on development of resistant peanut cultivar. Peanut Sci. 17:35-38.

17. Holbrook, C. C., and Noe, J. P. 1992. Resistance to the peanut root-knot nematode (Meloidogyne arenaria) in Arachis hypogaea. Peanut Sci. 19:35-37.

18. Holbrook, C. C., Timper, P., and Culbreath, A. K. 2003. Resistance to tomato spotted wilt virus and root-knot nematodes in peanut interspecific breeding lines. Crop Sci. 43:1109-1113.

19. Holbrook, C. C., Timper, P., and Xue, H. Q. 2000. Evaluation of the core collection approach for identifying resistance to Meloidogyne arenaria in peanut. Crop Sci. 40:11721175 .

20. Holbrook, C. C., Timper, P., and Xue, H. Q. 2000. Introgression of nematode and tomato spotted wilt resistance into cultivated peanut. Agron. Abstr. (2000): 194

21. Hopkins, M. S, Casa, A. M., Wang, T., Mitchell, S. E., Dean, R. E., Kochert, G. D. and Kresovich, S. 1999. Discovery and characterization of polymorphic simple sequence repeats (SSR) in peanut. Crop Sci. 39:12431247.

22. Huang, G., Allen, R., Davis, E. L., Baum, T. J., and Hussey, R. S. 2006. Engineering broad root-knot resistance in transgenic plants by RNAi silencing of a conserved and essential root-knot nematode parasitism gene. Proc. Natl. Acad. Sci. USA 103:14302-14306.

23. Huang, G., Dong, R., Allen, R., Davis, E. L., Baum, T. J., and Hussey, R. S. 2006. A rootknot nematode secretory peptide functions as a ligand for a plant transcription factor. Mol. Plant-Microbe Interact. 19:463-470.

24. Hussey R. S., and Barker, K. R. 1973. A comparison of methods of collecting inocula for Meloidogyne spp., including a new technique. Plant Dis. Rep. 57:1025-1028

25. Kaloshian, I., Williamson, V. M., Miyao, G., Lawn, D. A., and Westerdahl, B. B. 1996. Resistance-breaking nematodes identified in California tomatoes. Calif. Agric. 50:18-19.

26. Koenning, S. R., and Barker, K. R. 1992. Relative damage functions and reproductive potentials of Meloidogyne arenaria and $M$. hapla on peanut. J. Nematol. 24:187-192.

27. Koenning, S. R., Overstreet, C., Noling, J. W., Donald, P. A., Becker, J. O., and Fortnum, B. A. 1999. Survey of crop losses in response to phytoparasitic nematodes in the United States. Suppl. J. Nematol. 31:587-618.

28. Lima, R. D, Brito, J. A., Dickson, D. W., Crow, W. T., Zamora, C. A., and Mendes, M. L. 2002. Enzymatic characterization of Meloidogyne spp. associated with ornamentals and agronomic crops in Florida, USA. (Abstr.) Nematology 4:173.

29. Minton, N. A., and Baujard, P. 1990. Nematode parasites of peanut. Pages 285-320 in: Plant Parasitic Nematodes in Subtropical Agriculture. M. Luc, R. A. Sikora, and J. Bridge, eds. CABI, Wallingford, UK.

30. Minton, N. A., McGill, J. F., and Golden, A. M. 1969. Meloidogyne javanica attacks peanut in Georgia. Plant Dis. Rep. 53:668.

31. Nelson, S. C., Simpson, C. E., and Starr, J. L. 1989. Resistance to Meloidogyne arenaria in Arachis spp. germplasm. J. Nematol. 21:654660.

32. Nelson, S. C., Starr, J. L., and Simpson, C. E. 1990. Expression of resistance to Meloidogyne arenaria in Arachis batizocoi and A. cardenasii. J. Nematol. 22:423-425.

33. Roberts P. A., Matthews, W. C., and Ehlers, J. D. 1996. New resistance to virulent root-knot nematodes linked to the $R k$ locus of cowpea. Crop Sci. 36:889-894.

34. Sasser, J. N. 1980. Root-knot nematodes: A global menace to agriculture. Plant Dis. 64:3641. 
35. Sharma, S. B., Smith, D. H., and McDonald, D. 1995. Host races of Meloidogyne javanica, with preliminary evidence that the "groundnut race" is widely distributed in India. Intl. Arachis Newsl. 15:43-45.

36. Simpson, C. E., Nelson, S. C., Starr, J. L., Woodard, K. E., and Smith, O. D. 1993. Registration of TxAG-6 and TxAG-7 peanut germplasm lines. Crop Sci. 33:1418.

37. Simpson, C. E., and Starr, J. L. 2001. Registration of 'COAN' peanut. Crop Sci. 41:918

38. Simpson, C. E., Starr, J. L., Church, G. T. Burow, M. D., and Paterson, A. H. 2003. Registration of 'NemaTAM' Peanut. Crop Sci. 43:1561.

39. Song, X. S., Sharma, S. B., and Hu, J. P. 1992. Occurrence and damage of root-knot nematode (Meloidogyne hapla Chitwood) on peanut in Shandong, China. Intl. Arachis Newsl. 12:34-36.

40. Song, X. S., Lan, W., Dong, W. B., and Min, P.
1995. Identification of resistance to root-knot nematode (Meloidogyne hapla Chitwood) in peanut germplasm. Acta Phytopathol. Sin. 25:139-141.

41. Stalker, H. T., Beute, M. K., Shew, B. B., and Barker, K. R. 2002. Registration of two rootknot nematode-resistant peanut germplasm lines. Crop Sci. 42:312-313.

42. Starr, J. L., Schuster, G. L., and Simpson, C. E. 1990. Characterization of the resistance to Meloidogyne arenaria in an interspecific Arachis hybrid. Peanut Sci. 17:106-108.

43. Starr, J. L., Simpson, C. E., and Lee, T. A. Jr. 1995. Resistance to Meloidogyne arenaria in advanced generation breeding lines of peanut. Peanut Sci. 22:59-61

44. Starr, J. L., Simpson, C. E., and Lee, T. A., Jr. 1999. Yield of peanut genotypes resistant to root-knot nematodes. Peanut Sci. 25:119-123.

45. Subrahmanyam, P., Ghanekar, A. M., Nolt, B.
L., Reedy, D. V. R., and McDonald, D. 1983. Resistance to groundnut diseases in wild Ara chis species. Proc. Int. Workshop Cytogenetics of Arachis. ICRISAT Center, Patancheru, India.

46. Timper, P., Holbrook, C. C., and Anderson, W. F. 2003. Reproduction of Meloidogyne spp. on resistant peanut genotypes from three breeding programs. J. Nematol. 35:417-421.

47. Tomaszewski, E. K., Khalili, M. A. M., ElDeeb, A. A., Powers, T. O., and Starr, J. L. 1994. Meloidogyne javanica parasitic on peanut. J. Nematol. 26:436-441.

48. Wheeler, T. A., and Starr, J. L. 1987. Incidence and economic importance of plant-parasitic nematodes on peanut in Texas. Peanut Sci. 14:94-96.

49. Williamson, V. M., and Hussey, R. S. 1996. Nematode pathogenesis and resistance in plants. Plant Cell 8:1735-1745. 